\title{
Large mammal community composition and density under a disturbance gradient in Northeast Costa Rica
}

\author{
Emily S. Khazan*1,2, Manuel Arias ${ }^{1} \&$ Luis M. Fernández ${ }^{1}$ \\ 1. Caño Palma Biological Station, Canadian Organization for Tropical Education and Rainforest Conservation \\ (COTERC), Tortuguero, Limón, Costa Rica; ekhazan@gmail.com*, station@coterc.org, lmfdezp@gmail.com \\ 2. Oregon State University Department of Integrative Biology. \\ * Correspondence
}

Received 12-I-2016. Corrected 10-VII-2016. Accepted 10-VIII-2016.

\begin{abstract}
Large mammal communities, integral components of Neotropical ecosystems, are increasingly threatened by habitat fragmentation and degradation due to anthropogenic pressures and climate change. Lowland Neotropical palm forests harbor diverse mammal communities, including threatened and endangered species. We monitored three transects in the Barra del Colorado Wildlife Refuge in Northeast Costa Rica from February 2014 until April 2015 documenting large terrestrial mammal and primate detections. Following established large mammal survey methodology, each transect was walked weekly alternating between early morning and late afternoon to maximize detection. The three transects represent three levels of anthropogenic disturbance with highest disturbance at the Cerro, followed by Caño Palma Biological Station (CPBS), and lowest levels in Tortuguero National Park (TNP). Overall we found higher diversity and increased presence of endangered species in TNP and the lowest diversity and lower presence of those species in the Cerro. Overall we detected 25 species; 19 at the Cerro, 22 in TNP and 23 at CPBS. TNP had the highest diversity as calculated by Simpson index (28.3) followed by CBPS (27.9), and the Cerro had the lowest diversity of mammals (2.27). The most influential species driving the differences of communities between the three transects included the white-lipped and collared peccaries, which were both present in higher densities in transects with lower disturbance and higher levels of protection, and domestic dogs which were present in higher densities at the Cerro. This study has documented baseline densities of large mammal communities in the wildlife refuge which can be used as preliminary data for future comparisons. As development is continuing in the region, including construction of a tourist trail at the Cerro, a continued monitoring is recommended to understand the effect of development on mammal communities. Rev. Biol. Trop. 64 (4): 1553-1564. Epub 2016 December 01.
\end{abstract}

Key words: large mammal, neotropical, tropical forest, disturbance, Costa Rica, mammal density.

Neotropical lowland forests are home to immense diversity including complex and varied mammalian communities (Turner, 1996; Carrillo, Wong, \& Cuarón, 2000). Costa Rica harbors over 240 species of mammals including several endemic species (Wainwright, 2002) of varying sizes, trophic levels, and ecological niches. Mammals are integral elements of their ecosystems as they contribute to nutrient cycling, seed dispersion, and seed predation (Stoner, Riba-Hernández, Vulinec, \& Lambert, 2007), among other ecosystem services.
In addition to the many ecological roles they play, mammals throughout the Neotropics hold importance in historical and cultural traditions including harvest for skins and meat.

Much of the biodiversity of Neotropical forests is increasingly threatened due to agricultural expansion, increasing rates of development/land settlement, and natural resource extraction all of which leads to habitat fragmentation and degradation (Gascon, Williamson, $\&$ da Fonseca, 2000). Many large mammals, like many other vertebrates (Perfecto, Rice, 
Greenberg, \& van der Voort, 1996) and invertebrates (Ewers, Thorpe, \& Didham, 2007; Khazan, 2014), are sensitive to fragmentation (Michalski \& Peres, 2007), hunting pressures (Hill et al., 1997), and anthropogenic disturbance as measured by level of governmental protection (Carrillo et al., 2000). In addition to anthropogenic pressures, natural phenomena such as variation in floristic composition of forests and flooding regime also affect diversity and abundance of tropical mammals (Haugaasen \& Peres, 2005).

Costa Rica is home to 10 endangered or threatened mammal species protected by CITES, and several more with declining populations according to the IUCN (Wainwright, 2002; IUCN, 2007). Despite its conservation oriented policies and extensive protected areas, many taxa are still threatened and declining in number because of natural (e.g. climatic factors) and anthropogenic causes (e.g. deforestation, hunting, and development). Longterm monitoring programs are essential to documenting population assemblages and densities, and changes over time. Such programs are particularly important given the extent of human impacts and current and predicted effects of climate change.

Many studies across Costa Rica have documented the diverse mammal communities across several Holdridge life zones (Holdridge, 1967; De Thoisy, Brosse, \& Dubois, 2008; Graham, Bulloch, \& Lewis, 2013). These and other large mammal studies employ a variety of detection methods, often coupling transects with camera traps. Documenting mammal signs along line transects, focusing on tracks, has been demonstrated to be a consistent, reliable, and affordable method for large mammal detection in the Neotropics (Dirzo \& Miranda, 1990; Peres, 1996; Michalski \& Peres, 2007; Munari, Keller, \& Venticinque, 2011). The present study was carried out in a region with extensive mud cover, an ideal substrate for detecting mammal tracks. The Barra del Colorado Wildlife Refuge is located in the Northeast corner of Costa Rica extending from the San Juan River (Costa Rica's border with
Nicaragua) South to the Southern tip of Tortuguero National Park, widening from South to North. The refuge, within the Lowland Atlantic wet rainforest life zone (Holdridge, 1967), is composed primarily of palm swamps dominated by Raphia taedigera and Manicaria saccifera (Myers, 1990). While palm swamps in the Neotropics harbor diverse mammalian populations and are important for the maintenance of these communities and movement of individuals (Yaap, Watson, \& Laurance, 2015), large mammal communities are not well documented or studied within the Barra del Colorado Wildlife Refuge. This is the first study to document the relative densities of large mammals within the wildlife refuge, examining three areas of different protection regimes and anthropogenic pressures.

The data used in this study come from a long-term, ongoing large mammal monitoring project run by Caño Palma Biological Station. The goals of this study were (1) document the large mammal community within the Barra del Colorado Wildlife Refuge and Tortuguero National Park, (2) compare relative densities of large mammal species across three transects of varying governmental protection and anthropogenic disturbance, and (3) use the data and subsequent analysis to inform local ministry of environment officials, and help in the design of conservation measures for the continued and extended protection of mammals of the region. We predicted to find a gradient of diversity corresponding with the gradient of anthropogenic disturbance across our three transects. Thus, we expected to find a more diverse large mammal community in the more heavily protected Tortuguero National Park with higher densities of commonly hunted or otherwise sensitive species. In concert, we expected that the most disturbed transect, the Cerro, would harbor the lowest level of diversity.

\section{MATERIALS AND METHODS}

Study site: We used three forest transects, the Cerro, Caño Palma Biological Station (CPBS), and Tortuguero National Park (TNP), 
located within the Tortuguero Conservation Area (ACTo) in Northeast Costa Rica. The conservation area is composed of TNP, which was established in 1975, and the Barra del Colorado Wildlife Refuge, created in 1985. The refuge's Southern border is with the national park to the end extends North to the San Juan River, the border of Costa Rica and Nicaragua. Together, these protected areas are intended to provide contiguous habitat between the Indo Maíz Reserve in Southeastern Nicaragua South into Northeastern Costa Rica, forming the largest contiguous protected area of Lowland Atlantic tropical wet forest, approximately 111000 hectares (Holdridge, 1967; Lewis et al. 2010).

The Barra del Colorado Wildlife Refuge is protected under the Costa Rican Ministry of Environment and Energy (MINAE), subject to a lesser degree of protective vigilance than national parks. While designated for the protection of wildlife and natural resources, the refuge harbors several settlements, including San Francisco de Tortuguero which is home to approximately 600 people. Many of the homes within the refuge have been privately owned prior to the establishment of the refuge in 1985 . However, due in part to its remoteness and lack of law enforcement personnel, establishment of squatters and building of structures continues. In addition to illegal construction, hunting still takes place within the refuge, though to a lesser extent within the last ten years (M. Arias personal observation). The most commonly hunted mammal species include Central American agouti (Dasyprocta punctata Gray, 1842), lowland paca (Cuniculus paca Linnaeus, 1766), and both collared (Pecari taja$c u$ Linnaeus, 1758) and white-lipped peccary (Tayassu pecari Link, 1795).

We walked one transect within the national park. The other two transects were within the refuge, North of the national park at CPBS and at the base of a large hill near the town of San Francisco, referred to as the Cerro (Fig. 1). The three transects represent different levels of environmental protection and anthropogenic disturbance, as well as different natural flooding regimes. The number of transects within each type of protected area was restricted due to the conditions of the habitat (e.g. intense periodic flooding), spatial constraints, research permits, and logistical issues. CPBS experiences the most flooding of the three transects; there are often weeks during which the forest is flooded $>1 \mathrm{~m}$ (CPBS unpublished data), followed by TNP which only occasionally floods. During particularly rainy months, the Cerro often has standing water along the study transect, however, the majority is always accessible and tracks visible (CPBS unpublished data). We compensated for the lack of site replication with sampling intensity (weekly) and study duration (more than one year), which have provided with robust datasets for each transect and minimize the possibility of false absences (MacKenzie, 2005; MacKenzie \& Royle, 2005).

Survey protocol: The monitoring protocol followed MacKenzie (2005), using presence/ absence data to determine plot occupancy and density of different species. This design

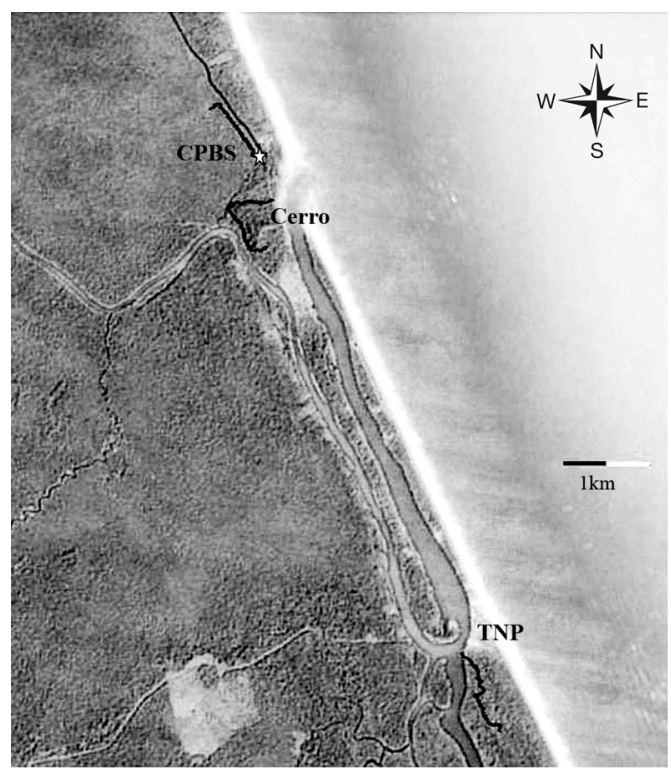

Fig. 1. Study region encompassing the Northern edge of Tortuguero National Park (TNP) and the Southern extreme of the Barra del Colorado Wildlife Refuge including the transects at Caño Palma Biological Station (CPBS) and the Cerro. 
combines methods, using multiple discrete visits and a single observer (i.e. M. Arias as leader; see below) conducting multiple surveys. Surveys were separated by one week allowing for old, previously counted tracks to disappear (MacKenzie, 2005). The transects were established following Peres (1999); cut with a machete, directed with a compass, and marked every $50 \mathrm{~m}$ with flagging and using a handheld GPS (Garmin GPSmap 62s). We walked each transect weekly, alternating between the early morning $(6: 00 \mathrm{~h})$ and the afternoon (14:00 h) to maximize detection, as these times represent peak activity of several diurnal mammal species (Peres, 1999). Surveys took place under a variety of weather conditions, including heavy rains, and were only cancelled if water levels were too high to detect any tracks over the course of an entire transect.

M. Arias led all surveys, always walking in front as the most experienced team member in detecting and identifying tracks. At least one trained staff member and up to three trained volunteers followed and assisted in track detection and identification. Each time we encountered a track or heard or saw a mammal, we documented the species, number of individuals, direction of tracks, and location coordinates. Identity of tracks was confirmed in the field using different field guides (Marineros \& Martinez, 1998; Reid, 2003). After recording the data, we erased tracks with sticks or our boots to prevent double-counting over time. All species occurrences within a $50 \mathrm{~m}$ section of transect were documented including if the animal was walking along our cut transect or if it passed perpendicular or diagonal to it (determined by directionality of tracks). Because of the diversity of opposums and the difficulty of species determination solely based on tracks, we grouped the common opossum (Didelphis marsupialis Linnaeus, 1758), Virginia opossum ( $D$. virginiana Kerr, 1792), wooly opossum (Caluromys (Mallodelphys) derbianus Waterhouse, 1841), and gray four-eyed opossum (Philander opossum Linnaeus, 1758) detections. They were listed as "unidentified opossum".
We established the transect within the national park in February 2014 which serves as the start date for this dataset which terminates on April 30th 2015. At the end of April, construction began on a raised trail around the base of the Cerro between the beginning and terminus of our mammal transect. We did not include data collected after the beginning of trail construction in order to document the mammalian community present prior to this large disturbance.

To prevent pseudoreplication, we recorded each species only once per $50 \mathrm{~m}$ sub-section. Monkey detections were dealt with differently, as the detection methods included vocalization and visualization. As we could not be certain if the monkeys seen were also the ones calling, detection by vocalization was only used if that species of monkey was not seen, and vocalizations were only included once per survey and counted as one individual. If we both saw and heard monkeys, we only used the visualization data in analyses and included all individuals counted. Individual monkey groups when seen were only documented once per survey, even if the group moved to a different sub-section of the transect. Other social species like whitelipped and collared peccaries groups were counted as single entities, but unlike monkeys, were recorded each time presence of the group was seen, even in sequential $50 \mathrm{~m}$ sub-sections (Carrillo et al., 2000).

Using Kruskal-Wallis tests, performed in SPSS v12 (SPSS Inc., Chicago, Illinois, USA), we compared densities of mammals, based on sightings and track detections, across the three transects. These comparisons were made only within species because of the differences in detection probability (conspicuousness) of species. While species-specific comparisons were conducted separately, in order to more broadly examine the communities of the three transects, we performed an analysis of similarity (ANOSIM) using Bray-Curtis distances. Despite the dissimilarity of detection probabilities, we felt this analysis appropriate because of the consistency with which the data were collected and because of the value of examining the data 
holistically. Because of the non-normality of the data, we used square-root transformed data, and analyzed it in PAST3 (Hammer, Harper, \& Ryan, 2001). The ANOSIM was followed by a SIMPER analysis performed in R (version 3.0.2, R Core Development Team 2013) to better understand which species drove the community-level differences across the three transects and as a complement to the singletaxa K-W tests. We also performed an NMDS in PAST using square-root transformed data to visualize the differences between the three transects at the community level.

\section{RESULTS}

Over the course of the study period, we surveyed CPBS 47 times, TNP 51 times, and the Cerro 53 times (Table 1). In total across all three transects, we detected 25 species; 19 at the Cerro, 22 in TNP and 23 at CPBS. Based on Simpson's index, the highest diversity and species evenness was at TNP, followed by CPBS, and the lowest was at the Cerro (Table 2). However not all species were used in subsequent analyses; we only used species encountered $\geq 3$ times over the course of the study in any transect when conducting the Kruskal-Wallis tests (Fig. 2), thus excluding the giant anteater (Myrmecophaga tridactyla Linnaeus, 1758), silky anteater (Cyclopes didactylus Linnaeus, 1758), jaguarondi (Puma yagouaroundi SaintHilaire, 1803), coati (Nassua narica Linnaeus, 1766), and different species of squirrels.

Through the Kruskal-Wallis tests, we found significant differences in densities of 12 species (Fig. 2). The only two species with higher densities at the Cerro compared with CPBS and TNP included the nine-banded armadillo (Dasypus novemcintus Linnaeus, 1758) and domestic dog (Canis lupus familiaris Linnaeus, 1758). At the Cerro, CPBS, and TNP we encountered 2.188, 1.377, and 1.051 dog tracks per trail kilometer respectively. The number of detections in the Cerro, thus the relative density of dogs there was marginally higher than at $\operatorname{CPBS}(\mathrm{H}=-2.313 ; \mathrm{p}=0.062)$, and significantly higher than in TNP $(\mathrm{H}=1.968 ; \mathrm{p}$ $<0.001)$. Armadillo detections were also significantly higher in the Cerro compared with CPBS $(\mathrm{H}=-4.053 ; \mathrm{p}<0.001)$ and TNP $(\mathrm{H}$ $=2.726 ; \mathrm{p}=0.019)$. Overall, TNP had higher densities of the largest and most endangered mammals including jaguars (Panthera onca Linnaeus, 1758) and white-lipped peccaries (Tayassu pecari, Link 1795). Jaguar tracks per trail kilometer were significantly higher in TNP than the Cerro $(0.533 / \mathrm{km}$ vs. $0.015 / \mathrm{km} ; \mathrm{H}$ $=-4.452 ; \mathrm{p}<0.001)$ and CPBS $(0.533 / \mathrm{km}$ vs. 0.182.km; $\mathrm{H}=-3.090 ; \mathrm{p}=0.006)$. A similar,

TABLE 1

Summary of survey effort over the study period (February 2014-April 2015) including total distance hiked, total survey time, and mean survey length separated by transect

\begin{tabular}{ccccc} 
Transect & Surveys & Km (Total) & Hours (Total) & Mean \pm SD \\
CPBS & 47 & 50.4 & $73: 01: 00$ & $1: 33 \pm 24.38$ \\
TNP & 51 & 65 & $83: 57: 00$ & $1: 42 \pm 24.39$ \\
Cerro & 53 & 67.5 & $69: 58: 00$ & $1: 19 \pm 20.22$ \\
\hline
\end{tabular}

TABLE 2

Species diversity, evenness, and diversity for all three transects calculated using Simpson's index

\begin{tabular}{cccc} 
Transect & Dominance & Evenness & Diversity (Simpson) \\
Cerro & 0.234 & 0.203 & 4.272 \\
TNP & 0.035 & 1.181 & 28.335 \\
CBPS & 0.036 & 1.035 & 27.958 \\
\hline
\end{tabular}


Canine

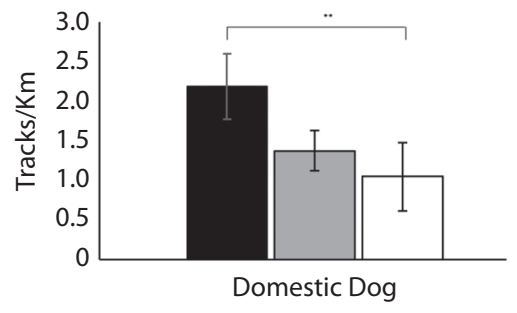

Marsupials

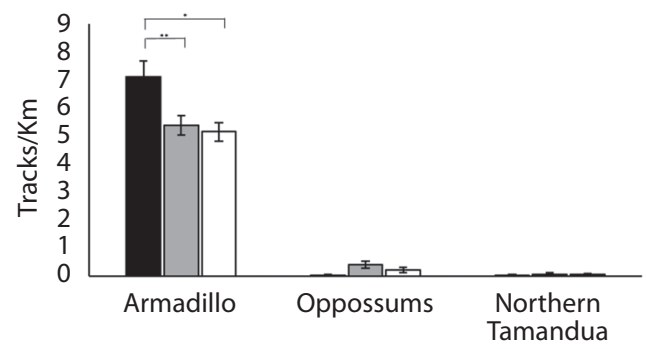

Felid

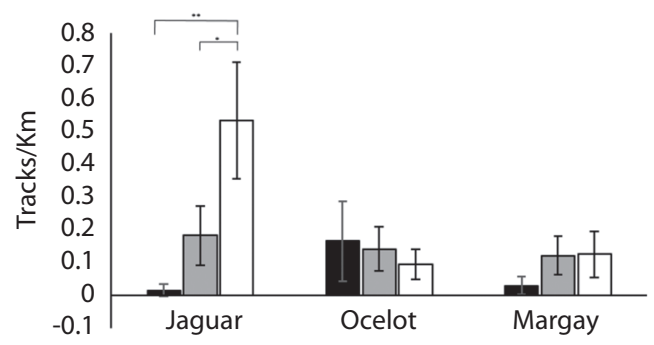

Rodents

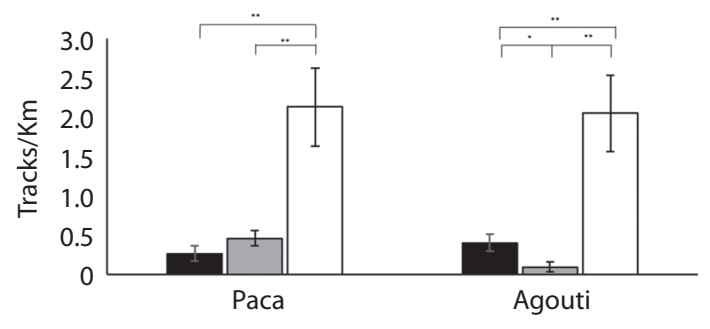

Ungulates

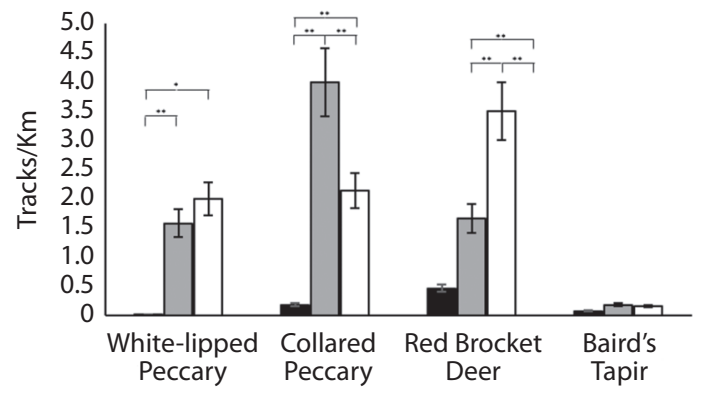

Small Carnivores

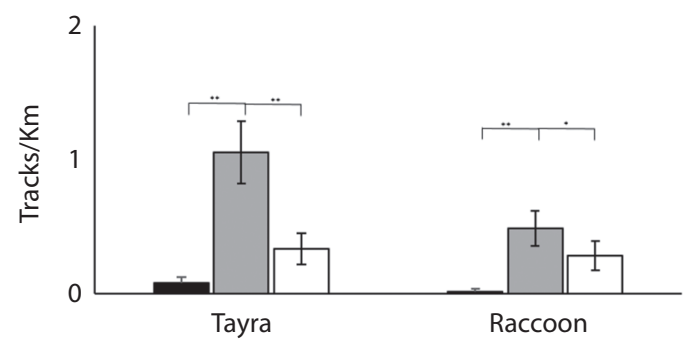

Primates

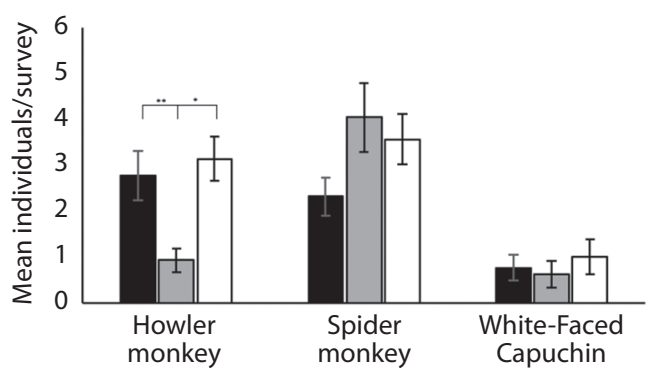

- Cerro $\square$ CPBS $\square$ TNP

Fig. 2. Mean mammal density with standard error bars. Kruskal-Wallis species-specific comparisons across the three study transects separated by taxonomic group; $* \mathrm{p}<0.05 ; * * \mathrm{p}<0.01$. 
but less extreme trend was documented with white-lipped peccaries for which relative abundance was much higher in TNP than the Cerro $(\mathrm{H}=-5.894 ; \mathrm{p}<0.001)$, and marginally higher than at CPBS $(H=2.365 ; \mathrm{p}=0.054)$.

We encountered significantly more mantled howler monkeys (Alouatta palliata Gray, $1848)$ at the Cerro compared with CPBS ( $\mathrm{H}=$ 2.465; $\mathrm{p}=0.041)$ and more howler monkeys at TNP compared to CPBS $(\mathrm{H}=-3.960 ; \mathrm{p}$ $<0.001)$; however found no differences in density of Geoffroy's spider monkeys (Ateles geoffroyi Kuhl, 1820) or white-headed capuchins (Cebus capucinus Linnaeus, 1758) across the three transects (Fig. 2).

The analysis of similarity (ANOSIM) demonstrated significant differences between the large mammal communities of the three transects (global $\mathrm{R}=0.467, \mathrm{P}=0.001$; Table 3). The SIMPER analysis established which species drive the community-level differences (Table 3). Using square-root transformed data (as used in the ANOSIM), we performed a non-metric multidimensional scaling (NMDS) ordination (Fig. 3), which shows the scatter of species and grouping of communities within each transect. Both the collared and whitelipped peccaries drove differences between all three of the pairwise comparisons (Table 3). As a direct reflection of human impact, domestic dogs also contribute a great deal to the differences between all transects.

\section{DISCUSSION}

As predicted, we found higher diversity of large mammals in Tortuguero National Park, followed by Caño Palma Biological Station, and the lowest level of diversity and density of most animals at the Cerro. We predicted to find fewer commonly hunted species and top predators at the Cerro compared with TNP and CPBS because of the proximity to human settlements. We also expected that the mammal community diversity would increase with decreasing anthropogenic pressure.

The most influential animals driving these differences include white-lipped and collared peccaries both of which require large tracts of land for foraging and are hunted for food, and domestic dogs, which directly represent anthropogenic pressures given their close associations

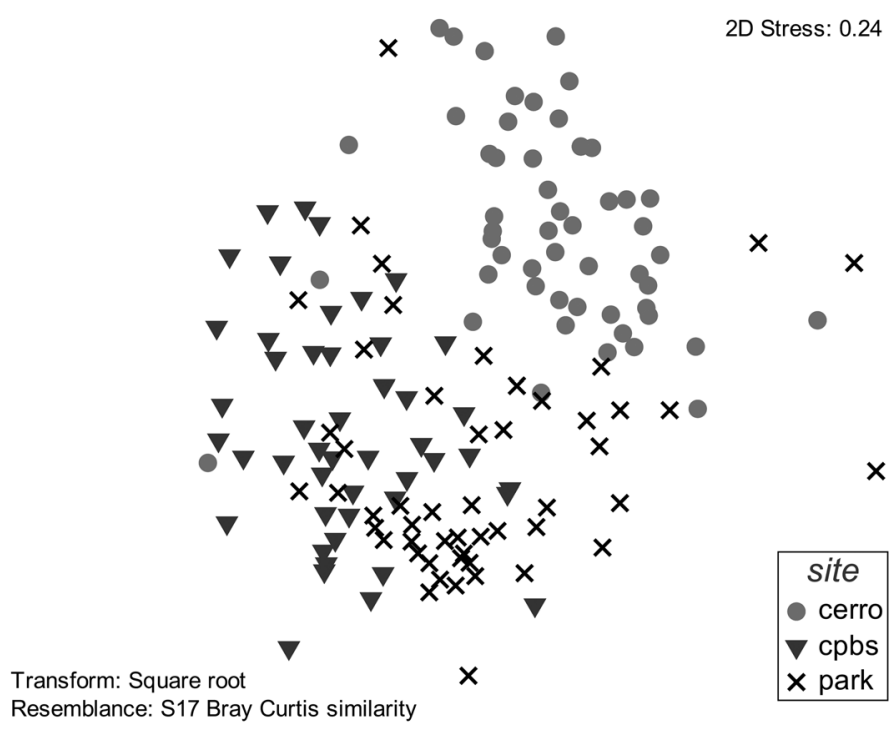

Fig. 3. Nonmetric multidimensional scaling (NMDS) visualization using square-root transformed data and Bray-Curtis distance of the large mammal communities of all three study transects. Cerro in red circles; TNP in black Xs; CPBS in blue triangles. 


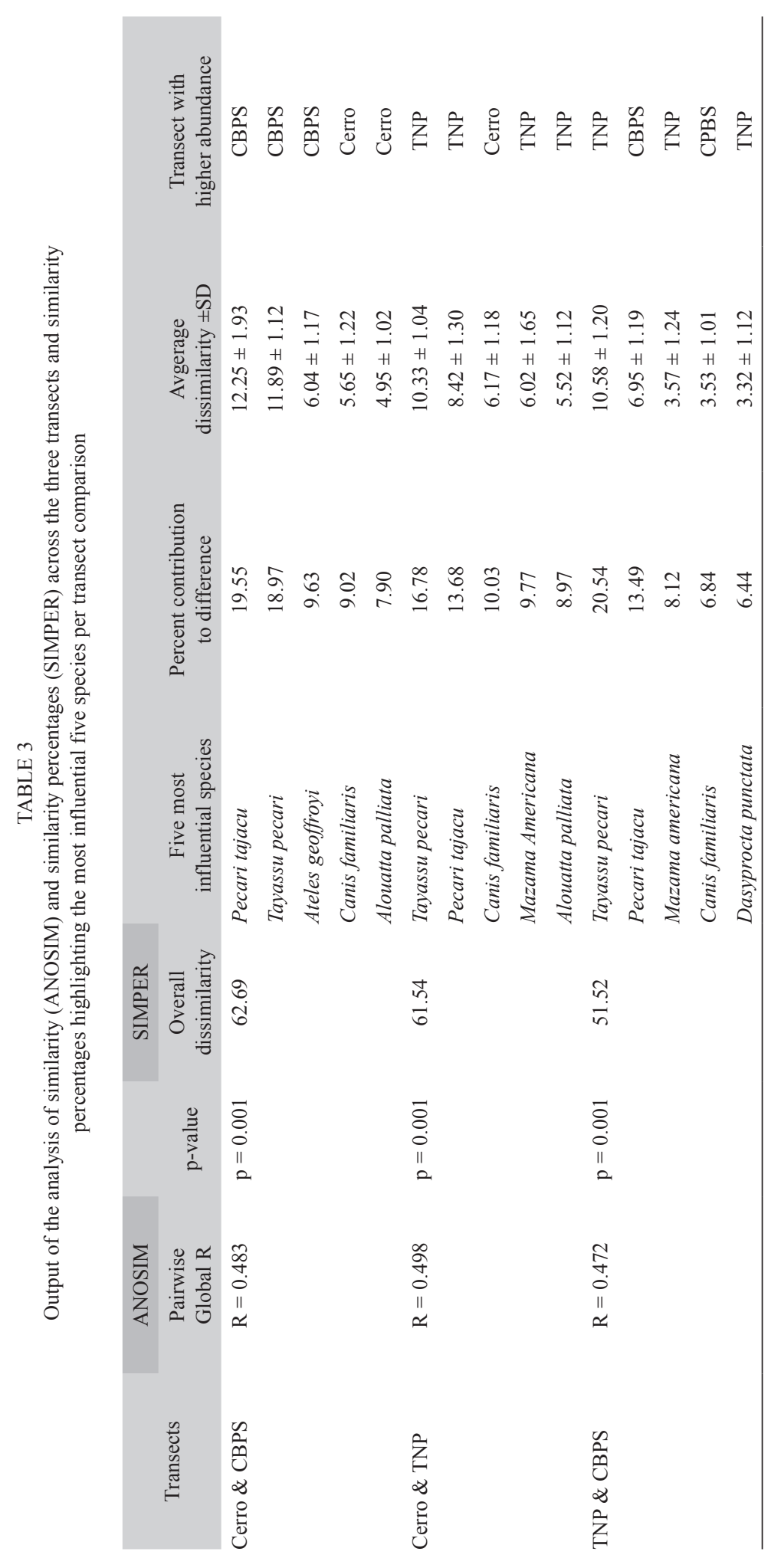


with human settlements. Jaguars, while not largely influential based on the SIMPER analysis, represent an important animal found in significantly higher abundance in the more protected, larger TNP than the other two transects. The higher presence of jaguars on the transects within larger tracts of contiguous forest and with lower levels of disturbance helps to explain the reverse trend in ocelot abundance, as jaguars can predate ocelots (GonzalezMaya, Navarro-Arquez, \& Schipper, 2010) and may displace ocelots given their role as intraguild predators (De Oliveira \& Pereira, 2014).

We encountered the highest density of domestic dogs at the Cerro, and secondarily at CPBS. The majority of the dog tracks found at CPBS was found close to the station and were most likely from the three guard dogs that live at the biological station and occasionally enter the forest. The low relative density of domestic dogs at TNP reflects its high level of protection and distance from permanent settlements. The only other terrestrial mammals that we found in significantly higher densities at the Cerro, compared with the other two transects, was the nine-banded armadillo and agouti. The difference in armadillo densities is likely due to (1) robustness of armadillos to disturbance (Michalski \& Peres, 2007), (2) the lack of hunting of armadillos in the area, and (3) the fact that they live in subterranean burrows which are much more frequently flooded at CPBS and TNP than the Cerro which in much of the transect never floods. Similarly for agoutis, frequent flooding makes seeds for feeding and nesting sites/shelter inaccessible. Ocelots were found in slightly higher densities in the Cerro compared with the other two transects in concert with the opposite trend in jaguar density. The two animals were seldom found on the same transect at the same time or even within a few weeks of each other, implying that as larger, more apex predators, jaguars displace other predators spatiotemporally, as has been demonstrated in other wild cats (Gil-Sánchez, Jaramillo, \& Barea-Azcón, 2015).

While the majority of the differences in density of terrestrial mammals can be attributed the proximity to and influence of humans (i.e. higher disturbance leads to less diverse and abundant large mammal communities), the same does not hold for primate communities. Monkeys are seldom hunted or kept as pets and seem not be affected by human settlements in the area. We found significantly higher relative densities of mantled howler monkeys at the Cerro and TNP, compared with CBPS. As those two sites flood much less frequently and thus have more floristic diversity compared to the palm dominated forest of CPBS (Lewis et al., 2010), there is more available foliage for howler monkeys to eat. The marginally higher density of Geoffory's spider monkeys at CPBS compared to the Cerro and TNP is probably a reflection of the presence of a resident troupe at the station which commonly feeds on the few large fruiting trees close to the station buildings.

Overall, we found a diverse and complex large mammal community inhabiting the region in and around Caño Palma Biological Station. Similarly diverse communities have been described throughout Costa Rica (Wainwright, 2002; Daily, Ceballos, Pacheco, Suzan, \& Sánchez-Azofeifa, 2003; Yaap et al., 2015) and specifically in other palm swamps in the country (Yaap et al., 2015). Despite being an under-studied habitat type, the importance of the palm dominated swamps of Northeast Costa Rica cannot be discounted for the maintenance of populations of ecologically invaluable and vulnerable mammals. Continued and improved vigilance of protected areas will be integral in maintaining these communities as they currently exist by preventing hunting and further habitat degradation and destruction. Sustaining this monitoring program will be invaluable for documenting and analyzing long-term changes in communities and for understanding the mechanisms behind such changes.

The data presented in this study concluded at the end of April 2015 when construction on a raised trail around the base of the Cerro began. The trail meets the end of our mammal transects and together they create a trail that circumvents nearly the entire base of the hill. This trail, 
commissioned by the Costa Rican Ministry of Energy and the Environment (MINAE), will be managed for tourism, allowing groups accompanied with tour guides to walk the raised concrete path. While the opening of the Cerro may reduce the effect of mammal hunting in that area, it also has potential for increasing human disturbance in the form of pollution, noise, artificial light, and defoliation. Negative effects of anthropogenic disturbance in the form of tourism (i.e. increased presence of humans to a non accustomed native fauna) have been documented in other mammals including primates (Berman, Li, Ogawa, Ionica, \& Yin, 2007). The fate of future management of the trail remains unknown. Continued monitoring of the mammalian community around the Cerro and other sites in the region is necessary for detecting and documenting any changes in community assemblage and/or densities of animals in the area (Pellet \& Schmidt, 2005). As Caño Palma Biological Station and affiliated researchers continue to collect it, monitoring data will help inform conservation and management practices and shed light on the effects of land management for touristic purposes.

\section{ACKNOWLEDGMENTS}

We thank Aaron Geheber and Jessica Beyer for statistical support and comments on earlier versions of the manuscript. Elias Bader and many interns and volunteers of Caño Palma Biological Station for help with data collection. We also thank Kym Snarr, Greg Mayne, and Jonathan Williams for working to establish the long-term mammal monitoring program, as well as the COTERC board. MINAE and the staff of Tortuguero National Park, particularly Victor Hugo Montero generously permitted access to the park and logistical help. The research was conducted under permit SINAC-ACTO-D-RES-028-2014.

\section{RESUMEN}

Composición y densidad de las comunidades de grandes mamíferos bajo un gradiente de alteración en el noreste de Costa Rica. Las comunidades de grandes mamíferos, componentes integrales de los ecosistemas neotropicales, se encuentran cada vez más amenazadas debido a la fragmentación del hábitat y a su degradación por presiones antropogénicas y por el cambio climático. Los bosques de palmeras de zonas bajas neotropicales albergan comunidades diversas de mamíferos, incluyendo especies amenazadas y en peligro. Hemos monitoreado tres transectos en el Refugio Nacional de Vida Silvestre Barra del Colorado en el noreste de Costa Rica, desde febrero 2014 hasta abril 2015, registrando grandes mamíferos terrestres y primates. Siguiendo métodos establecidos de muestreos de mamíferos grandes, caminábamos cada transecto una vez por semana alternando entre la maña y la tarde para maximizar la detección. Estos tres transectos representan tres niveles de alteración antropogénica, encontrándose la más fuerte en el Cerro, seguido de la Estación Biológica Caño Palma (CPBS) y, con la menor presión, el Parque Nacional Tortuguero (TNP). En general, hemos encontrado una mayor diversidad y mayor presencia de especies en peligro de extinción en TNP y una menor diversidad y una menor presencia de estas especies en el Cerro. En esta investigación, detectamos 25 especies en total; 19 en el Cerro, 22 en el TNP, y 23 en CPBS. TNP tenía el más alto nivel de diversidad según el índice Simpson (28.3) seguido por CBPS (27.9), y el Cerro tenía el nivel de diversidad más bajo (2.27). Las especies que influyen en mayor medida con la diferenciación de las comunidades entre los tres transectos incluyen los pecarís cariblanco y de collar, ambos encontrados en mayor densidad en los transectos con menores alteraciones y altos niveles de protección, y los perros domésticos, los cuales aparecen en mayor densidad en el Cerro. Este estudio sirve de base para documentar las comunidades de grandes mamíferos en el refugio y puede ser usado para futuras comparaciones. Debido al continuo desarrollo de la región, incluyendo la construcción de un sendero para turistas en el Cerro, el monitoreo continuo es imprescindible para el entendimiento de los efectos del desarrollo en las comunidades de mamíferos.

Palabras clave: grandes mamíferos, neotropical, selva tropical, perturbación, alteración, Costa Rica, densidad de mamíferos.

\section{REFERENCES}

Berman, C. M., Li, J. H., Ogawa, H., Ionica, C. S., \& Yin, H. (2007). Primate tourism and infant risk among Macaca thibetana at Mt. Huangshan, China. International Journal of Primatology, 28, 123-1141.

Carrillo, E., Wong, G., \& Cuarón, A. D. (2000). Monitoring mammal populations in Costa Rican protected areas under different hunting restrictions. Conservation Biology, 14, 1580-1591.

Daily, G. C., Ceballos, G., Pacheco, J., Suzan, G., \& Sánchez-Azofeifa, A. (2003). Countryside biogeography 
of neotropical mammals: conservation opportunities in agricultural landscapes of Costa Rica. Conservation Biology, 17, 1814-1826.

De Oliveira, T. G., \& Pereira, J. A. (2014). Intraguild predation and interspecific killing as structuring forces of Carnivoran communities in South America. Journal of Mammalian Evolution, 21(4), 427-436.

De Thoisy, B., Brosse, S., \& Dubois, M. A. (2008). Assessment of large-vertebrate species richness and relative abundance in Neotropical forest using linetransect censuses: what is the minimal effort required? Biodiversity and Conservation, 17, 2627-2644.

Dirzo, R., \& Miranda, A. (1990). Contemporary neotropical defaunation and forest structure, function, and diversity- A sequel to John Terborgh. Conservation Biology, 4(4), 444-447.

Ewers, R. M., Thorpe, S., \& Didham, R. K. (2007). Synergistic Interactions between Edge and Area Effects in a Heavily Fragmented Landscape. Ecology, 88(1), 96-106.

Gascon, C., Williamson, B. G., \& da Fonseca, G. A. B. (2000). Receding Forest Edges and Vanishing Reserves. Science, 288(5470), 1356-1358.

Gil-Sánchez, J. M., Jaramillo, J., \& Barea-Azcón, J. M. (2015). Strong spatial segregation between wildcats and domestic cats may explain low hybridization rates in the Iberian Peninsula. Zoology, 118(6), 377-385.

González-Maya, J. F., Navarro-Arquez, E., \& Schipper, J. (2010). Ocelots as prey items of jaguars: a case from Talamanca, Costa Rica. Cat News, 53, 11-12

Graham, K. E., Bulloch, M. J., \& Lewis, T. R. (2013). Foraging behaviour of three primate species in a Costa Rican coastal lowland tropical wet forest. Biodiversity Journal, 4(2), 327-334.

Hammer, Ø., Harper, D. A. T., \& Ryan, P. D. (2001). PAST-Palaeontological statistics. Retrieved froma http://www.uv.es/ pardomv/pe/2001_1/past/pastprog/past.pdf

Haugaasen, T., \& Peres, C. A. (2005). Mammal assemblage structure in Amazonian flooded and unflooded forests. Journal of Tropical Ecology, 21(2),133-145.

Hill, K., Padwe, J., Bejyvagi, C., Bepurangi, A., Jakugi, F., Tykuarangi, R., \& Tykurangi, T. (1997). Impact of hinting on large vertebrates in the Mbaracayu Reserve, Paraguay. Conservation Biology, 11(6), 1339-1353.

Holdridge, L. R. (1967). Ecología basada en zonas de vida (3rd ed.). San José, Costa Rica: Editorial del Instituto Interamericano de Cooperación para la Agricultura (IICA).
International Union for Conservation of Nature (IUCN). (2007). IUCN red list of threatened species. Gland, Switzerland: IUCN. Retrieved from http://www. iucnredlist.org/

Khazan, E. S. (2014). Tests of biological corridor efficacy for conservation of a Neotropical giant damselfly. Biological Conservation, 177, 117-125.

Lewis, T., Grant, P., Quesada, M. G., Ryall, C., Laduke, T. C., \& Road, W. (2010). A botanical survey of Caño Palma Biological Station (Estación Biológica Caño Palma), Tortuguero, Costa Rica. Brenesia, 73-74, 73-84.

MacKenzie, D. I., \& Royle, J. A. (2005). Designing occupancy studies: general advice and allocating survey effort. Journal of Applied Ecology, 42(6), 1105-1114.

MacKenzie, D. I. (2005). What are the issues with presence-absence data for wildlife managers. Journal of Wildlife Management, 69(3), 849-860.

Marineros, L., \& Martínez, F. (1998). Mamíferos de Honduras. Tegucigalpa, Honduras: INADES.

Michalski, F., \& Peres, C. A. (2007). Disturbance-Mediated Mammal Persistence and Abundance-Area Relationships in Amazonian Forest Fragments. Conservation Biology, 21(6), 1626-1640.

Munari, D. P., Keller, C., \& Venticinque, E. M. (2011). An evaluation of field techniques for monitoring terrestrial mammal populations in Amazonia. Mammalian Biology, 76(4), 401-408.

Myers, R. L. (1990). Ecosystems of the World 15: Forested Wetlands. Amsterdam: Elsevier.

Pellet, J., \& Schimdt, B. R. (2005). Monitoring distributions using call surveys: estimating site occupancy, detection probabilities and inferring absence. Biological Conservation, 123(1), 27-35.

Peres, C. A. (1996). Population status of white-lipped Tayassu pecari and collared peccaries, T. tajacu in hunted and unhunted Amazonian forests. Biological Conservation, 77, 115-123.

Peres, C. A. (1999). General Guidelines for Standardizing Transect Surveys for Tropical Forest Primates. Neotropical Primates, 44(1), 11-16.

Perfecto, I., Rice, R. A., Greenberg, R., \& van der Voort, M. E. (1996). Shade coffee: A disappearing refuge for biodiversity. BioScience, 46(8), 598-608.

R Core Development Team (2013) R version 3.0.2. R Project for Statistical Computing, Vienna, Austria. Retrieved froma www.r-project.org 
Reid, F. (2003). A field guide to the mammals of Central America and Southeast Mexico. Oxford, USA: University Press.

Stoner, K., Riba-Hernández, P., Vulinec, K., \& Lambert, J. E. (2007). The role of mammals in creating and modifying seedshadows in tropical forests and some possible consequences for their elimination. Biotropica, 39(3), 316-327.
Turner, I. M. (1996). Species loss in fragments of tropical rain forest: a review of the evidence. Journal of Applied Ecology, 33, 200-209.

Wainwright, M. (2002). The Mammals of Costa Rica - A natural history and field guide. USA: Cornell University Press.

Yaap, B., Watson, H., \& Laurance, W. F. (2015). Mammal use of Raphia taedigera palm stands in Costa Rica's Osa Peninsula. Mammalia, 79(3), 357-362. 